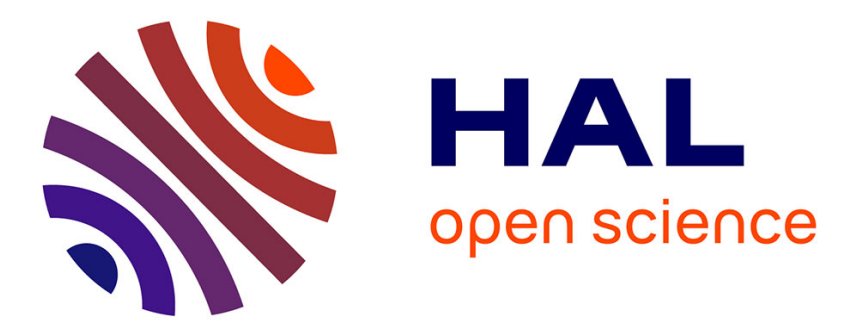

\title{
Observation of photon recycling in strain-balanced quantum well solar cells
}

D. Johnson, I. Ballard, A. Bessière, K. Barnham, J.P. Connolly, M. Mazzer, C. Calder, G. Hill, J.S. Roberts

\section{- To cite this version:}

D. Johnson, I. Ballard, A. Bessière, K. Barnham, J.P. Connolly, et al.. Observation of photon recycling in strain-balanced quantum well solar cells. Applied Physics Letters, 2007, 90 (21), pp.213505. 10.1063/1.2742334 . hal-02927569

\section{HAL Id: hal-02927569 \\ https://hal.science/hal-02927569}

Submitted on 28 Sep 2020

HAL is a multi-disciplinary open access archive for the deposit and dissemination of scientific research documents, whether they are published or not. The documents may come from teaching and research institutions in France or abroad, or from public or private research centers.
L'archive ouverte pluridisciplinaire HAL, est destinée au dépôt et à la diffusion de documents scientifiques de niveau recherche, publiés ou non, émanant des établissements d'enseignement et de recherche français ou étrangers, des laboratoires publics ou privés. 


\section{Observation of Photon Recycling in Strain-Balanced Quantum Well Solar Cells}

D.C. Johnson ${ }^{1}$, I.M. Ballard ${ }^{1}$, A. Bessière ${ }^{2}$, K.W.J. Barnham ${ }^{1}$, J.P. Connolly ${ }^{1}$, M. Mazzer ${ }^{1}$, C. Calder ${ }^{3}$, G. Hill ${ }^{3}$, J.S. Roberts ${ }^{3}$

${ }^{1}$ Experimental Solid State Physics, Blackett Laboratory, Imperial College London, SW7 2AZ, UK,

${ }^{2}$ 1LECA (UMR 7575 CNRS), Ecole Nationale Supérieure de Chimie de Paris, 75005 Paris

${ }^{3}$ EPSRC National Centre for III-V Technologies, University of Sheffield, Mappin

Street, Sheffield S1 3JD, UK

Photon recycling in strain balanced quantum well solar cells grown on distributed Bragg reflectors has been observed as a suppression of the dark current and a change in electroluminescence spectra. Comparing devices grown with and without distributed Bragg reflectors we have demonstrated up to a $33 \%$ reduction in the ideality $n=1$ reverse saturation current. Furthermore, to validate the observations we demonstrate how both the measured dark currents and electroluminescence spectra fit very well to a photon recycling model. Verifying our observations with the model then allows us to calculate optimised device designs. 
Strain-balanced quantum well solar cells (SB-QWSC) have exhibited efficiencies similar to GaAs p-n devices [1] and are proving to be a viable path to achieving efficiencies beyond the long-standing GaAs single junction world record [2]. Growing strain balanced quantum wells in the intrinsic region of a GaAs p-i-n solar cell increases the short-circuit current $\left(\mathrm{J}_{\mathrm{SC}}\right)$, due to the lower absorption threshold energy in the well. The increase in $\mathrm{J}_{\mathrm{SC}}$ exceeds the reduction in open-circuit voltage $\left(\mathrm{V}_{\mathrm{OC}}\right)$ provided the compressively strained InGaAs wells are balanced by the tensile strained GaAsP barriers [1]. Further efficiency enhancement has been achieved by growing the devices on a distributed Bragg reflector (DBR) such that incident photons, which are not absorbed by the device initially, are reflected back into the device. The second pass absorption further increases $\mathrm{J}_{\mathrm{SC}}$ [3]. Another benefit of growing SB-QWSCs on a DBR substrate, as we report here, is that the device dark current is suppressed when compared to devices grown on GaAs substrates. Reduction in dark current is only observed when the device is operating in a regime where radiative recombination is the dominant recombination mechanism [4]; this behaviour is indicative of photon recycling (PR) or photon self-absorption effects. In this letter we will present experimental and theoretical evidence of PR in SB-QWSCs.

PR occurs when photons that are emitted from a semiconductor device are subsequently re-absorbed. Considering that this process may occur several times for a single photon, the effect is often observed experimentally as an increase in the minority carrier lifetime $[5,6]$; therefore, one can also expect to observe PR as a reduction in the dark current. Dumke [7] was one of the first to describe PR quantitatively while more recently Asbeck's photon recycling factor [8] has been used widely both theoretically and experimentally. Evidence of PR has been readily demonstrated in semiconductor devices such as double-heterostructures [9, 10] or light emitting diodes (LED) [11-13], whereas, results from solar cells have been rather more elusive [14]. Patkar et al [15] were one of the only groups to demonstrate PR as a reduction of the dark current, however, this was in LEDs rather than solar cells. Here we present the first direct evidence for dark-current reduction due to PR in solar cells and confirm this through the observation of changes in the electroluminescence (EL) spectra.

Results presented here have been observed in devices with three different SBQWSC designs (referred to as Design 1,2 and 3) which vary only in the number and depth of the quantum wells. Each SB-QWSC device design was gown on both a DBR and a GaAs substrate for comparison. To ensure that the wafers with and without DBRs were grown in as similar conditions as possible a pre-grown DBR wafer and a n-type GaAs substrate were placed down- and up-stream, respectively, in the metal organic vapour phase epitaxy (MOVPE) reactor and both overgrown in the same gas flow. The quantum wells are grown with alloys of $\operatorname{In}_{\mathrm{X}} \mathrm{Ga}_{1-\mathrm{X}} \mathrm{As}$ from $\mathrm{x}=0.11$ to $\mathrm{x}=$ 0.22 and the barriers are grown with alloys of $\mathrm{GaAs}_{\mathrm{y}} \mathrm{P}_{1-\mathrm{y}}$ where $\mathrm{y}=0.91$. The DBRs were grown using alternating layers of material with low $\left(\mathrm{Al}_{0.8} \mathrm{Ga}_{0.2} \mathrm{As}\right)$ and high $\left(\mathrm{Al}_{0.13} \mathrm{Ga}_{0.87} \mathrm{As}\right)$ refractive indices. The DBR layer thicknesses were designed to maximize absorption of normal incident light by the quantum wells. To reduce the series resistance presented by the DBR, intermediate layers of $\mathrm{Al}_{0.5} \mathrm{Ga}_{0.5} \mathrm{As}$ are grown between each DBR layer. Further details of the DBR design can be found in Ref 3 .

Devices were processed into fully metalised, $800 \mathrm{um}$ diameter, mesa structures for dark current characterization as well as concentrator devices with $3.7 \mathrm{~mm}$ diameter mesas and 11\% metalisation [16] for EL characterisation. Fully metalised devices are used such that series resistance effects on the ideality $n=1$ behaviour of the devices 
can be kept to a minimum while operation under illuminated conditions can still be predicted [17]. All devices were grown and processed at the EPSRC National Centre for III-V Technologies.

A computer controlled Keithley 238 SMU was used to measure the dark current response of the fully metalised devices. Measurements were made using the four point method and pulsed current sourcing to reduce heating. All measurements were taken at $25^{\circ} \mathrm{C}$ using a Peltier cooled stage. The measurements made in the high current region of 20 control and DBR devices of Design 2 are presented in Fig. 1 The measurements were subsequently fit to a two exponential model, based on the ideal Shockley diode equation [18], shown below:

$J=J_{01} \cdot e^{q \cdot\left(V-J \cdot R_{s}\right) /\left(n_{1} \cdot k \cdot T\right)}+J_{02} \cdot e^{q \cdot\left(V-J \cdot R_{s}\right) /\left(n_{2} \cdot k \cdot T\right)}$

where $\mathrm{J}_{01}$ and $\mathrm{J}_{02}$ are reverse saturation currents, $\mathrm{n}_{1}$ and $\mathrm{n}_{2}$ are ideality factors, $\mathrm{V}$ is the applied bias, $R_{S}$ is the series resistance, $k$ is the Boltzmann constant and $T$ is the temperature. For the purposes of fitting, the ideality factor $\mathrm{n}_{1}$ is fixed at 1 . The first term in eqn. 1 dominates at high bias and corresponds to quantum well radiative recombination, which we have shown to be more important than the ideal Shockley recombination in the field-free $\mathrm{p}$ and $\mathrm{n}$ regions [4]. The ideality $\mathrm{n}_{2}$ in the second term is fit to a value of $\sim 2$ which corresponds to non-radiative Shockley-Read-Hall (SRH) recombination.

By fitting the measured data to eqn 1 we obtain values for $\mathrm{J}_{01}, \mathrm{~J}_{02}, \mathrm{n}_{2}$ and $\mathrm{R}_{\mathrm{S}}$. The average $J_{01}$ and $J_{02}$ values obtained by fitting results on $\sim 15$ devices for each design are listed in Table I. The ideality $\mathrm{n}=1$ reverse saturation current $\left(\mathrm{J}_{01}\right)$ obtained from the fit is reduced by $>25 \%$ for all three device designs and by $33 \%$ for Designs 1 and 3. The latter reduction would result in absolute efficiency enhancement of $\sim 0.3 \%$ at concentration levels of $\sim 500 \mathrm{x}$ entirely due to PR as a result of the DBR substrate. One can see that while $\mathrm{J}_{01}$ for the DBR cell is reduced compared to the control in all cases, the non-radiative contribution $\mathrm{J}_{02}$ is largely unchanged for Designs 1 and 2; the third design exhibited irregular behaviour in the ideality $n \sim 2$ region, which is why the $\mathrm{J}_{02}$ values could not be fit.

To validate the observed reduction in the $\mathrm{J}_{01}$ reverse saturation current $\mathrm{a}$ photon recycling model has been developed. The EL spectra and, therefore, dark current are calculated using the method outlined in Refs $[19,20]$. The net photon flux exiting the surface of a semiconductor device can be described using the generalised Planck equation for a non-black body. Integrating the photon flux density over energy, one can obtain the radiative dark-current for a given bias or quasi-Fermi level separation. This method requires calculation of device absorptivity. The absorptivity of an arbitrary device design is calculated using a complex refractive index which is calculated from an experimental quantum efficiency and device thickness. The resulting refractive index is then used along with the matrix method [21] to calculate the absorptivity of a stack of thin films including anti-reflection coatings, the window layer, active layer and DBR. This method takes into account multiple passes of photons and interference effects in the structure; these effects are important to consider in SB-QWSCs since the quantum wells have relatively low absorptivity, which can result in multiple reflections before emitted photons are re-absorbed. All calculations are done using the low-AOD spectrum $\left(913 \mathrm{~W} / \mathrm{m}^{2}\right)$ while assuming ideal behaviour with zero series resistance and 5\% optical shading.

EL spectra are measured by driving devices into forward bias using a Keithley 238 source measure unit (SMU); while maintaining the device at $25^{\circ} \mathrm{C}$ using a Peltier cooled stage. The resulting emission spectrum is measured using a computer 
controlled charge-coupled device. Fig. 2 shows a comparison between the resulting measured EL spectrum and the modeled spectrum of a SB-QWSC grown on a DBR (Design 1). In both the measured and modeled spectrum one can see the distinct Fabry-Perot oscillations in the emission and that the results from our model fit the experiment quite well. By integrating the EL spectrum over energy we are also able to calculate the expected radiative contribution to the device dark current. Fig. 1 shows both the measured dark currents for the control and DBR devices of Design 2 as well as the predicted radiative contribution to the dark current as calculated from our model. The reduction of the dark current is evident in both the measurements and the calculated values from our model. Table I compares the calculated reverse saturation currents with the average measured parameters for all three designs. One can see that the model quite accurately describes the ideality $n=1$ component of the measured dark currents in both relative and absolute terms.

Given close agreement between the model and experiment we have calculated DBR designs in an effort to achieve the highest overall device efficiency. As we have seen previously, a DBR can enhance the $\mathrm{J}_{\mathrm{SC}}$ of a SB-QWSC considerably [3]. Similarly, we have shown here that a SB-QWSCs grown on a DBR benefits from an increase in $\mathrm{V}_{\mathrm{OC}}$ due to $\mathrm{PR}$. However, to increase both $\mathrm{J}_{\mathrm{SC}}$ and $\mathrm{V}_{\mathrm{OC}}$ it is desirable to maximise the DBR optical "stop band" magnitude and width while reducing the angular dependence of the reflectivity. Given the DBR material $\left(\mathrm{Al}_{1-\mathrm{X}} \mathrm{Gas}_{\mathrm{X}} \mathrm{As}\right)$ and series resistance limit imposed on the number of DBR periods, the DBR reflectivity can be optimised in one of two ways - growing multiple DBRs with varying stop band wavelengths and growing chirped DBRs (CDBR) [22].

Using the model, we calculated the efficiency of a 50 shallow quantum well CDBR (201/2 period $1 \%$ chirp) SB-QWSC at $350 x$ concentration while varying the initial thickness of the DBR layers. One can see in Fig. 3 that there are two distinct efficiency maxima. The bottom left (indicated by the letter A) corresponds to a DBR optimised to reflect normal incident photons of energies which are readily absorbed by the quantum wells and so the efficiency enhancement is primarily due to an increase in $\mathrm{J}_{\mathrm{SC}}$. On the other hand, the peak at the bottom right of the plot (indicated by the letter B) corresponds to a DBR which primarily reflects photons of energies which are absorbed by the quantum wells at off-normal incidence resulting in PR. The critical angle for photons to escape from the GaAs-Air surface is $\sim 16$ degrees and so any photons emitted towards the front surface at an angle greater than this will be reflected back into the device. If the reflected photons are not re-absorbed by the quantum wells, they may also be reflected at the back of the device by the off-normal incidence reflectivity of the DBR. Therefore, photons emitted outside of the GaAs-Air escape cone may then be re-absorbed by the quantum wells and thus result in a reduction of the device dark current. By designing a device with two $10^{1 / 2}$ period $1 \%$ chirped DBRs each of which is designed for one of the peak efficiencies in Figure 3, the calculated device $\mathrm{J}_{\mathrm{SC}}$ and $\mathrm{V}_{\mathrm{OC}}$ values were both enhanced. Table II summarises the results of calculated efficiencies for devices 50 well SB-QWSC devices grown with no DBR, and grown on CDBRs optimized for $\mathrm{V}_{\mathrm{OC}}, \mathrm{J}_{\mathrm{SC}}$, and both. An further increase in efficiency can be realised by growing the SB-QWSC on two CDBRs with different reflectivity.

In conclusion PR in SB-QWSCs has been demonstrated in both the dark current and the EL for the first time in a solar cell. Both effects are also well described by a model based on radiative recombination. We have also demonstrated that PR can have a considerable impact on the overall conversion efficiency of a SB-QWSC. We 
expect optimized device and DBR designs to enhance the PR effect which should, in conjunction with increased normal incidence absorption, result in $>2 \%$ (absolute) increase in efficiency. This work not only demonstrates experimental evidence of PR in SB-QWSCs but also the effect of DBR design on PR and ultimately overall device efficiency.

[1] N. J. Ekins-Daukes, K. W. J. Barnham, J. P. Connolly, J. S. Roberts, J. C. Clark, G. Hill, and M. Mazzer, "Strain-balanced GaAsP/InGaAs quantum well solar cells," Applied Physics Letters, 75, pp. 4195-4197, 1999.

[2] M. A. Green, K. Emery, D. L. King, S. Igari, and W. Warta, "Solar cell efficiency tables (version 26)," Progress in Photovoltaics: Research and Applications, 13, pp. 387-392, 2005.

[3] D. C. Johnson, I. Ballard, K. W. J. Barnham, D.B.Bushnell, J. P. Connolly, M. C. Lynch, T. N. D. Tibbits, N. J. Ekins-Daukes, M. Mazzer, R. Airey, G. Hill, and J. S. Roberts, "Advances in Bragg stack quantum well solar cells," Solar Energy Materials and Solar Cells, 87, pp. 168-179, 2004.

[4] K. W. J. Barnham, I. M. Ballard, D. B. Bushnell, J. P. Connolly, R. Day, N. J. Ekins-Daukes, D. C. Johnson, C. Lim, M. Lynch, M. Mazzer, T. N. D. Tibbits, C. Calder, G. Hill, and J. S. Roberts, Observation of ideal dark-current behaviour in strain-balanced quantum well solar cells, presented at Proc. 19th European Photovoltaic Solar Energy Conference and Exhibition, Paris, 2004, pp. 328-331.

[5] R. K. Ahrenkiel, D. J. Dunlavy, B. Keyes, S. M. Vernon, T. M. Dixon, S. P. Tobin, K. L. Miller, and R. E. Hayes, "Ultralong minority-carrier lifetime epitaxial GaAs by photon recycling," Applied Physics Letters, 55, 1989.

[6] G. B. Lush, H. F. MacMillian, B. M. Keyes, D. H. Levi, M. R. Melloch, R. K. Ahrenkiel, and M. S. Lundstrom, "A study of minority carrier lifetime versus doping concentration in n-type GaAs grown by metalorganic chemical vapour deposition," Journal of Applied Physics, 72, pp. 1436-1442, 1992.

[7] W. P. Dumke, "Spontaneous radiative recombination in semiconductors," Physical Review, 105, pp. 139-144, 1957.

[8] P. Asbeck, "Self-absorption effects on the radiative lifetime in GaAs-GaAlAs double heterostructures," Journal of Applied Physics, 48, pp. 820-822, 1977.

[9] T. Kuriyama, T. Kamiya, and H. Yanai, "Effect of photon recycling on diffusion length and internal quantum efficiency in GaAs-Alx Ga1-xAs heterostructures," Japanese Journal of Applied Physics, 16, pp. 465-477, 1977.

[10] I. Schnitzer, E. Yablonovitch, C. Caneau, and T. J. Gmitter, "Ultrahigh spontaneous emission quantum efficiency, 99.7\% internally and $72 \%$ externally, from AlGaAs/GaAs/AlGaAs double heterostructures," Applied Physics Letters, 62, 1992.

[11] I. Schnitzer, E. Yablonovitch, C. Caneau, T. J. Gmitter, and A. Scherer, "30\% external quantum efficiency from surface textured, thin-film light-emitting diodes," Applied Physics Letters, 63, 1993.

[12] E. F. Schubert, Y.-H. Wang, A. Y. Cho, L.-W. Tu, and G. J. Zydzik, "Resonant cavity light-emitting diodes," Applied Physics Letters, 60, 1992.

[13] E. Dupont, H. C. Liu, M. Buchanan, S. Chiu, and M. Gau, "Efficient GaAs light-emitting diodes by photon recycling," Applied Physics Letters, 76, pp. 46,2000 . 
[14] K. Zahraman, J. Guillaume, G. Nataf, B. Beaumont, M. Leroux, and P. Gibart, "High efficiency A10.2Ga0.8As/Si stacked tandem solar cells using epitaxial lift-off," Journal of Applied Physics, 33, pp. 5807-5810, 1994.

[15] M. P. Patkar, M. S. Lundstrom, and M.R. Melloch, "Characterization of photon recycling in thin crystalline GaAs light emitting diodes," Journal of Applied Physics, 78, pp. 2817-2822, 1995.

[16] J. C. Maroto, A. Marti, C. Algora, and G. L. Araujo, 1300 suns GaAs concentrator solar cell with efficiency over 23\%, presented at 13th European Photovoltaic Solar Energy Conf., Nice, 1995, pp. 343-348.

[17] T.N.D.Tibbits, I.M.Ballard, K.W.J.Barnham, R.Day, C.Lim, M.Lynch, M.Mazzer, J.S.Roberts, and R.Airey, Demonstration of additivity in strainbalanced quantum well solar cells and efficiency at high concentration, Orlando, 2005, pp. 587-590.

[18] W. Shockley, "The theory of p-n junctions in semiconductors and p-n junction transistors," Bell Systems Technical Journal, 28, pp. 435, 1949.

[19] J. Nelson, J. Barnes, N.J.Ekins-Daukes, B. Kluftinger, E. Tsui, K.W.J.Barnham, T. C. Foxton, T. Cheng, and J. S. Roberts, "Observation of suppressed radiative recombination in single quantum well p-i-n diodes," Journal of Applied Physics, 82, pp. 6240-6246, 1997.

[20] G. L. Araujo and A. Marti, "Absolute limiting efficiencies for photovoltaic energy conversion," Solar Energy Materials and Solar Cells, 33, pp. 213, 1994.

[21] H. A. Macleod, Thin Film Optical Filters, Third ed. Bristol: IOP Publishing, 2000.

[22] T. Saka, M. Hirotani, T. Kato, H. Susawa, and N. Yamauchi, "Bragg Reflector of GaAlAs/A1As Layers with Wide Bandwidth Applicable to Light-EmittingDiodes," Journal of Applied Physics, 73, pp. 380-383, 1993. 
Table I. Reverse saturation currents as calculated and fitted from measurement.

\begin{tabular}{lllll}
\hline & In fraction & Calculated & \multicolumn{2}{c}{ Measured } \\
Design \# & \multicolumn{1}{c}{$\mathrm{x}$} & $\mathrm{J}_{01}\left(\mathrm{x} 10^{-21} \mathrm{~A}\right)$ & $\mathrm{J}_{02}\left(\mathrm{x} 10^{-13} \mathrm{~A}\right)$ & $\mathrm{J}_{01}\left(\times 10^{-21} \mathrm{~A}\right)$ \\
\hline 1 Control & 0.11 & 1.7 & $3.2 \pm 0.4$ & $1.5 \pm 0.2$ \\
1 DBR & 0.11 & 1.2 & $2.9 \pm 0.7$ & $1.0 \pm 0.2$ \\
2 Control & 0.17 & 6.8 & $4.5 \pm 0.5$ & $8.9 \pm 0.3$ \\
2 DBR & 0.17 & 5.1 & $5.1 \pm 0.2$ & $6.7 \pm 0.1$ \\
3 Control & 0.22 & 1.8 & NA & $1.5 \pm 0.2$ \\
3 DBR & 0.22 & 1.3 & NA & $1.0 \pm 0.1$ \\
\hline
\end{tabular}


Table II. Calculated $\mathrm{V}_{\mathrm{OC}}, \mathrm{J}_{\mathrm{SC}}$ and efficiency $(\eta)$, at $350 \mathrm{x}$ concentration (low-AOD spectrum), of a 50 shallow well SB-QWSC grown on a GaAs substrate, a single $201 / 2$ period DBR optimised to increase $\mathrm{J}_{\mathrm{SC}}$, a single $201 / 2$ period DBR optimised to increase $\mathrm{V}_{\mathrm{OC}}$, and two $101 / 2$ period DBRs one of which is optimised for $\mathrm{J}_{\mathrm{SC}}$ and the other for $\mathrm{V}_{\mathrm{OC}}$ enhancement. All DBRs are chirped at $1 \%$ per period.

\begin{tabular}{lllll}
\hline DBR Design & $\mathrm{V}_{\mathrm{OC}}(\mathrm{V})$ & $\mathrm{J}_{\mathrm{SC}}(\mathrm{A} / \mathrm{m} 2)$ & $\mathrm{FF}(\%)$ & $\eta(\%)$ \\
\hline $\begin{array}{l}\text { None } \\
\text { Single CDBR }\end{array}$ & 1.15 & 257 & 90.1 & 29.2 \\
$\mathrm{~J}_{\mathrm{SC}}$ optimised & 1.16 & 267 & 89.8 & 30.5 \\
$\begin{array}{l}\text { Single CDBR } \\
\mathrm{V}_{\mathrm{OC}} \text { optimised }\end{array}$ & 1.19 & 259 & 88.9 & 30.1 \\
$\begin{array}{l}\text { Double CDBR } \\
\mathrm{J}_{\mathrm{SC}} \text { and } \mathrm{V}_{\mathrm{OC}}\end{array}$ & 1.17 & 266 & 90.2 & 30.7 \\
\hline
\end{tabular}




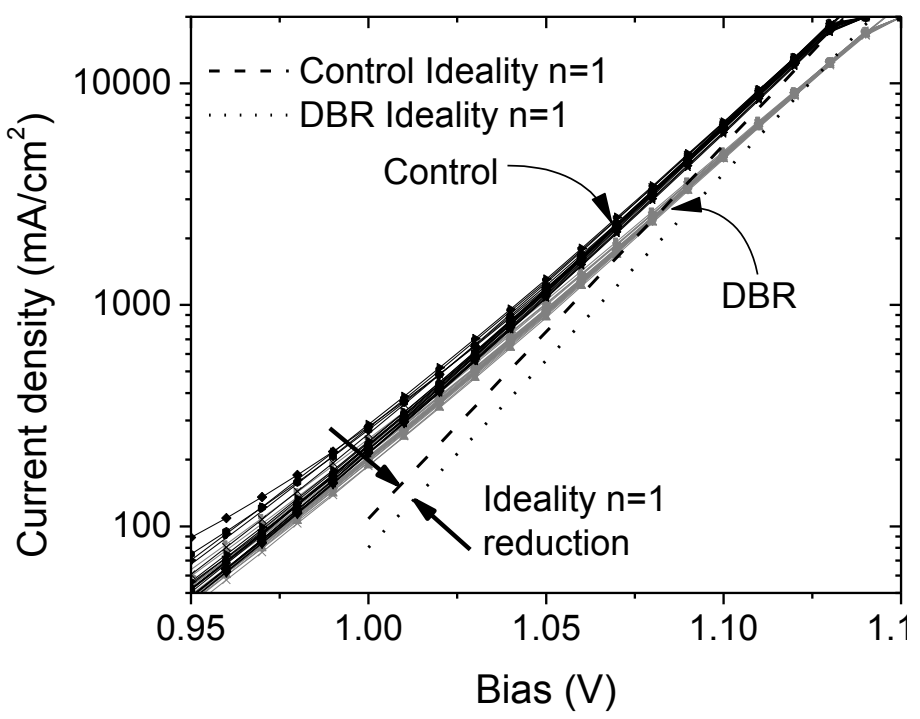

Figure 1. Measured dark current of shallow quantum well SB-QWSC grown on DBR (grey) and GaAs (black) substrates. Also shown are the calculated ideality $\mathrm{n}=$ 1 dark current components for the DBR (dotted) and Control (dashed). 


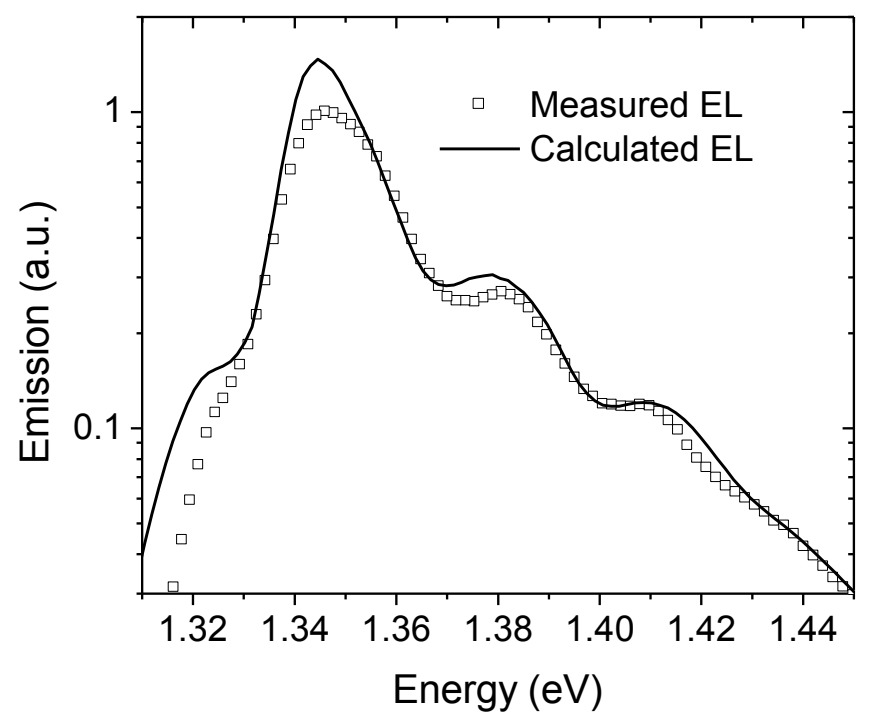

Figure 2. Measured (empty squares) and modeled (solid line) electroluminescence spectra of shallow quantum well DBR SB-QWSC. 


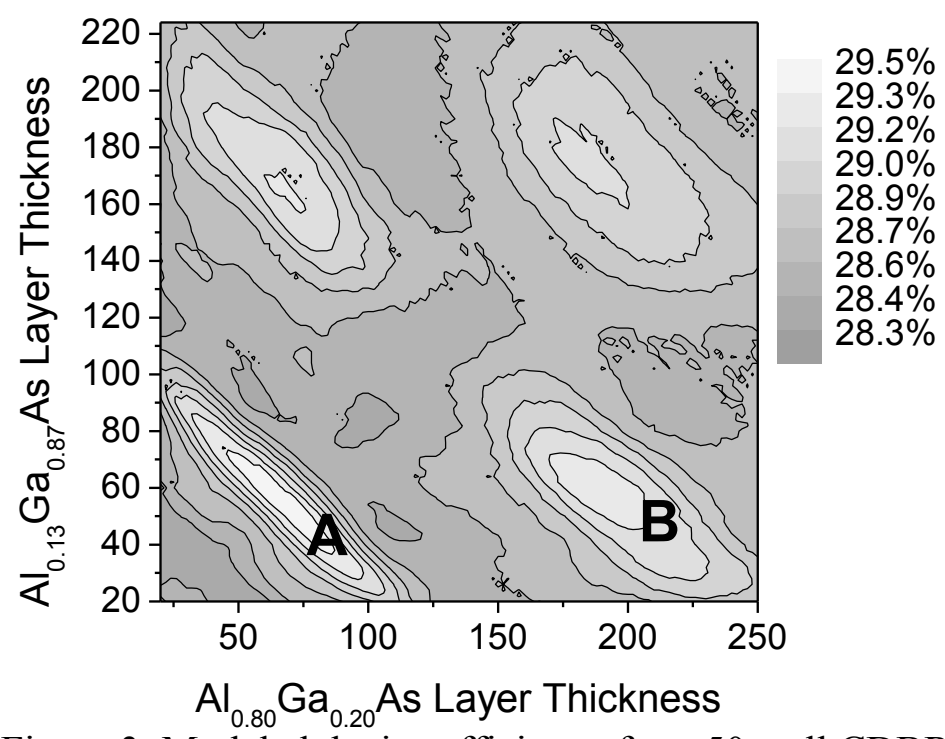

Figure 3. Modeled device efficiency for a 50 well CDBR SB-QWSC at 350x (lowAOD spectrum) concentration in the radiative limit, as a function of the initial layer thicknesses of a $\mathrm{Al}_{0.8} \mathrm{Ga}_{0.2} \mathrm{As} / \mathrm{Al}_{0.13} \mathrm{Ga}_{0.87} \mathrm{As} \mathrm{DBR}$ chirped at $1 \%$ per period. The high efficiency in the lower left (point $A$ ) is due to an increase in $\mathrm{J}_{\mathrm{SC}}$ while the lower right efficiency peak (point $\mathrm{B}$ ) is due to an increase in $\mathrm{V}_{\mathrm{OC}}$. 